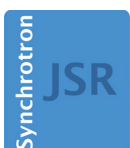

JOURNAL OF SYNCHROTRON RADIATION

ISSN 1600-5775

\section{Journal of Synchrotron Radiation: open call for new Main Editor to join leadership team}

The Journal of Synchrotron Radiation (JSR) is one of the ten leading journals published by the International Union of Crystallography (IUCr). In this context, JSR provides comprehensive coverage of the entire field of synchrotron radiation and free-electron laser (FEL) research including instrumentation, theory, computing and scientific applications in areas such as biology, nanoscience and materials science. While presently a hybrid journal with both fully open-access papers and papers accessible on a traditional subscription basis, it is planned that JSR will become a $100 \%$ open-access research journal in the near future.

At this time, we seek a new Main Editor of $J S R$. The successful candidate will work with the existing JSR Main Editors, the entire JSR Editorial Board, its Managing Editor and staff in the IUCr Editorial Office in Chester, UK, as well as the IUCr Journals Editorin-Chief, to take JSR through this important transition. The successful candidate will help provide dynamic leadership of $J S R$ through a smooth transition to open access while maintaining its leading position in the publication of synchrotron- and FEL-based research across all relevant fields.

In addition to sharing in the editorial workload for papers submitted to $J S R$, the Main Editors provide leadership for the journal's Editorial Board, scientific development and welfare. Working with the JSR Managing Editor and staff in Chester, the recently appointed IUCr Journals Commissioning Editors, and the Editor-in-Chief, the JSR Main Editors recruit new Co-editors, commission Lead and Feature Articles, as well as plan or commission Special Issues, including the recruitment of Special Issue Guest Editors. In all these aspects, please note that the IUCr is committed to improving gender and geographical balance while maintaining the highest scientific standards, and everyone associated with IUCr Journals is expected to respect these guidelines.

Appointment criteria for IUCr Journals Main Editors are given at https://journals. iucr.org/services/coeditors/handbook/meappointment_criteria.html, but some flexibility will be applied in appointing the best possible candidate at this time for what is anticipated to be a key role for pioneering the future of $J S R$, and IUCr journals as a whole.

Please write in confidence by 31 August 2020 to the Editor-in-Chief (eic@iucr.org) and Executive Managing Editor (med@iucr.org), enclosing your CV, a list of your 20-25 most important publications, your vision for the future development of the Journal of Synchrotron Radiation in 500 words, and a full list of publications.

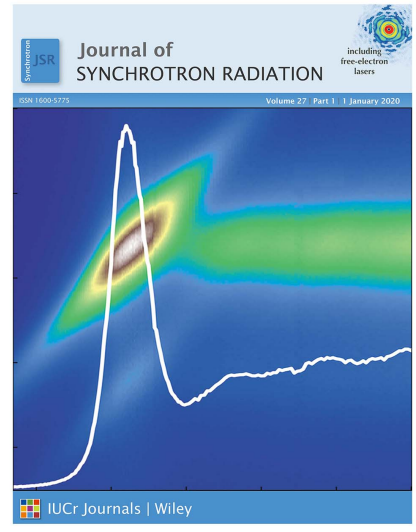

